\title{
Calibration of a complex activated sludge model for the full-scale wastewater treatment plant
}

\author{
Ewa Liwarska-Bizukojc • Dorota Olejnik • \\ Rafal Biernacki $\cdot$ Stanislaw Ledakowicz
}

Received: 24 August 2010/Accepted: 12 January 2011/Published online: 4 February 2011

(C) The Author(s) 2011. This article is published with open access at Springerlink.com

\begin{abstract}
In this study, the results of the calibration of the complex activated sludge model implemented in BioWin software for the full-scale wastewater treatment plant are presented. Within the calibration of the model, sensitivity analysis of its parameters and the fractions of carbonaceous substrate were performed. In the steady-state and dynamic calibrations, a successful agreement between the measured and simulated values of the output variables was achieved. Sensitivity analysis revealed that upon the calculations of normalized sensitivity coefficient $\left(S_{i, j}\right) 17$ (steady-state) or 19 (dynamic conditions) kinetic and stoichiometric parameters are sensitive. Most of them are associated with growth and decay of ordinary heterotrophic organisms and phosphorus accumulating organisms. The rankings of ten most sensitive parameters established on the basis of the calculations of the mean square sensitivity measure $\left(\delta_{j}^{\mathrm{msqr}}\right)$ indicate that irrespective of the fact, whether the steadystate or dynamic calibration was performed, there is an agreement in the sensitivity of parameters.
\end{abstract}

Keywords Activated sludge $\cdot$ Calibration $\cdot$ Model parameters $\cdot$ Sensitivity analysis $\cdot$ Wastewater

E. Liwarska-Bizukojc $(\varangle) \cdot$ D. Olejnik · R. Biernacki Institute of Environmental Engineering,

Technical University of Lodz, Al. Politechniki 6, 90-924 Lodz, Poland

e-mail: ewa.liwarska-bizukojc@p.lodz.pl

R. Biernacki

Water Supply System and Sewer-Zgierz Ltd,

ul. A. Struga 45, 95-100 Zgierz, Poland

\section{S. Ledakowicz}

Department of Bioprocess Engineering,

Technical University of Lodz, ul. Wolczanska 213,

90-924 Lodz, Poland

$\begin{array}{ll}\text { Abbreviations } & \\ \text { ASM } & \text { Activated sludge model } \\ \text { AS/AD } & \text { Activated sludge/anaerobic digestion } \\ \text { AOB } & \text { Ammonia oxidising biomass } \\ \text { ANAMMOX } & \text { ANaerobic AMMonia OXidizers } \\ \text { ARD } & \text { Average relative deviation } \\ m_{i} & \text { Measured value of the output variable } \\ n & \text { Number of output variables } \\ N & \text { Number of observations } \\ \text { NOB } & \text { Nitrite oxidising biomass } \\ \text { OHOs } & \text { Ordinary heterotrophic organisms } \\ p_{i} & \text { Predicted value of the output variable } \\ \text { PE } & \text { Population equivalent } \\ \text { PAOs } & \text { Phosphorus accumulating organisms } \\ \text { PHA } & \text { Poly-hydroxy-alkanoates } \\ \text { SD } & \text { Standard deviation } \\ x_{i} & \text { Input variable } \\ y_{i} & \text { Output variable } \\ \text { WWTP } & \text { Wastewater treatment plant }\end{array}$

List of symbols

$b_{\text {aerob,A }} \quad$ Aerobic decay rate for AOB $\left(\right.$ day $\left.^{-1}\right)$

$b_{\text {aerob,N }} \quad$ Aerobic decay rate for NOB $\left(\right.$ day $\left.^{-1}\right)$

$b_{\mathrm{H}} \quad$ Aerobic decay rate for $\mathrm{OHO}\left(\mathrm{day}^{-1}\right)$

$b_{\mathrm{PAO}} \quad$ Aerobic decay rate for PAO $\left(\right.$ day $\left.^{-1}\right)$

$F_{\text {ac }} \quad$ Acetate (g COD g of readily degradable $\left.\mathrm{COD}^{-1}\right)$

$F_{\text {bs }} \quad$ Readily biodegradable

(g COD g COD tot $^{-1}$ )

$F_{\text {up }} \quad$ Non-biodegradable particulate

(g COD g COD tot $^{-1}$ )

$F_{\text {us }} \quad$ Non-biodegradable soluble

(g COD g COD tot $^{-1}$ )

$F_{\mathrm{xp}} \quad$ Non-colloidal slowly biodegradable

(g COD g of slowly degradable $\mathrm{COD}^{-1}$ ) 


\begin{tabular}{|c|c|c|c|}
\hline$k_{\mathrm{a}}$ & $\begin{array}{l}\text { Ammonification rate of soluble organic } \\
\text { nitrogen compound }\left(\mathrm{day}^{-1}\right)\end{array}$ & $\mu_{\max A}$ & $\begin{array}{l}\text { Maximum specific growth rate of } \mathrm{AOB} \\
\left(\mathrm{day}^{-1}\right)\end{array}$ \\
\hline$K_{\mathrm{NH}_{4}}$ & $\begin{array}{l}\text { Substrate }\left(\mathrm{N}-\mathrm{NH}_{4}{ }^{+}\right) \text {half saturation constant } \\
\left(\mathrm{mg} \mathrm{N} \mathrm{l}^{-1}\right)\end{array}$ & $\mu_{\operatorname{maxH}}$ & $\begin{array}{l}\text { Maximum specific growth rate of } \mathrm{OHO} \\
\text { under aerobic conditions }\left(\mathrm{day}^{-1}\right)\end{array}$ \\
\hline$K_{\mathrm{OA}}$ & $\begin{array}{l}\text { Oxygen half saturation constant for } \mathrm{AOB} \\
\left(\mathrm{mg} \mathrm{O}_{2} \mathrm{l}^{-1}\right)\end{array}$ & $\mu_{\operatorname{maxPAO}}$ & $\begin{array}{l}\text { Maximum specific growth rate of PAO } \\
\left(\text { day }^{-1}\right)\end{array}$ \\
\hline$K_{\mathrm{OH}}$ & $\begin{array}{l}\text { Oxygen half saturation constant for OHOs } \\
\left(\mathrm{mg} \mathrm{O}_{2} \mathrm{l}^{-1}\right) \\
\mathrm{P} \text { uptake half saturation constant }\left(\mathrm{mg} \mathrm{P}^{-1}\right)\end{array}$ & $\mu_{\text {maxP-limited }}$ & $\begin{array}{l}\text { Maximum specific growth rate of PAO } \\
\text { under phosphorus limiting conditions } \\
\left(\text { day }^{-1}\right)\end{array}$ \\
\hline
\end{tabular}

$K_{\mathrm{S}} \quad$ Substrate (COD) half saturation constant $\left(\mathrm{mg} \mathrm{COD}^{-1}\right)$

$K_{\mathrm{S} \text {,hydrolysis }} \quad$ Hydrolysis half saturation constant (-)

$K_{\mathrm{S}, \mathrm{PAO}} \quad$ Substrate (PHA) half saturation constant (mg COD $~^{-1}$ )

$K_{\text {S,P-limited }}$ Substrate (PHA) half saturation constant under phosphorus limiting conditions (mg COD l ${ }^{-1}$ )

$\mathrm{N}_{\text {tot }} \quad$ Total nitrogen concentration $\left(\mathrm{mg} \mathrm{N}^{-1}\right)$

$\mathrm{P}_{\text {tot }} \quad$ Total phosphorus concentration $\left(\mathrm{mg} \mathrm{P}^{-1}\right)$

$Q_{\text {eff }} \quad$ Effluent flow rate $\left(\mathrm{m}^{3}\right.$ day $\left.^{-1}\right)$

$Q_{\text {in }} \quad$ Influent flow rate $\left(\mathrm{m}^{3}\right.$ day $\left.^{-1}\right)$

$Q_{\text {in, R }} \quad$ Internal recirculation $\left(\mathrm{m}^{3}\right.$ day $\left.^{-1}\right)$

$Q_{\mathrm{R}} \quad$ Recirculated activated sludge $\left(\mathrm{m}^{3}\right.$ day $\left.^{-1}\right)$

$Q_{\mathrm{S} \text { ex }} \quad$ Excess sludge $\left(\mathrm{m}^{3}\right.$ day $\left.^{-1}\right)$

$S_{i, j}$

SRT

TKN

TSS

$Y_{\mathrm{A}}$

$Y_{\mathrm{H}}$

$Y_{\mathrm{H} \text {,anoxic }}$

$Y_{\text {lowPP }}$

$Y_{\mathrm{P} / \text { acetic }}$

$Y_{\mathrm{P} / \mathrm{PHAaerobic}}$ Amount of $\mathrm{P}$ stored per unit of PHA oxidized in aerobic conditions (mg P mg COD ${ }^{-1}$ )

$Y_{\text {P/PHAseq }}$ Amount of PHA stored when $1 \mathrm{mg}$ of acetate or propionate is sequestered (mg COD mg $\mathrm{COD}^{-1}$ )

$Y_{\mathrm{PO}_{4}} \quad$ Amount of $\mathrm{P}$ released per $1 \mathrm{mg}$ of substrate (mg P mg COD ${ }^{-1}$ )

\section{Greek symbols}

$\delta_{j}^{\mathrm{msqr}} \quad$ The mean square sensitivity measure

$\eta_{\text {anoxic,H }} \quad$ Anoxic growth factor

$\eta_{\text {anoxic, h }} \quad$ Rate reduction factor for hydrolysis under anoxic conditions

\section{Introduction}

Activated sludge models (ASMs) and models being a combination of ASMs (so-called ASM-based models) belong to the most commonly used approach in modeling of biological wastewater treatment processes. Since the publication of the first activated sludge model ASM1 in 1987, the complexity of these models has increased significantly [1]. It was due to the recognition of new phenomena and introduction of new variables and parameters expressing them into the models. As a result, the application of the models to the specific wastewater treatment plant (WWTP) became a more difficult and time-consuming task. In order to describe the overall behavior of biological processes in a WWTP, the model calibration is necessary.

Model calibration is understood as the estimation of the model parameters to fit a certain set of data obtained from the full-scale WWTP under study [2]. The operational data of WWTP should be checked and carefully introduced into the model as the input data within the calibration process [3]. Different calibration levels can be distinguished and several calibration protocols for the ASMs have been elaborated [4-7]. Sin et al. [8] summarized and compared in detail four calibration methodologies: Biomath-Calibration protocol, the Dutch Foundation of Applied Water Research (STOWA) calibration protocol, the Hochschulgruppe (HSG) guidelines and Water Environment Research Foundation (WERF) protocol. In spite of differences between these protocols, each of them includes two substantial stages, i.e. a steady-state and dynamic calibrations of the model. The authors of the aforementioned calibration procedures also emphasized the role of sensitivity analysis in the model calibration process. Sensitivity analysis should be performed in the steady-state and dynamic calibration stages to figure out, which parameters of the model are the most influential and need to be calibrated [6,9]. According to Vanrolleghem et al. [6], sensitivity analysis should be incorporated into the calibration protocol to minimize the efforts and optimize the overall calibration procedure. 
Although the ASM-family models are widespread used, the library of studies demonstrating the experiences of their calibration for a full-scale WWTP is relatively inconspicuous [2, 10, 11]. Thus, in this paper, a full-scale WWTP situated in the central Poland is under consideration. Moreover, the previous studies usually concerned one of the ASM-family models, whereas in the contemporary simulation software complex models being a combination of ASMs or an alternative to them are often implemented. So in this study, the new results of the calibration of the complex ASM implemented in BioWin software for the full-scale WWTP were supplied. The calibration procedure comprised sensitivity analysis of kinetic and stoichiometric model parameters as well as the fractions of carbonaceous substrate.

The main aim of this work is to verify the predictability of the BioWin activated sludge (AS) model under the dynamic conditions and select its most influential parameters.

\section{Materials and methods}

\section{Description of the WWTP}

The WWTP in the city of Zgierz (Poland) treats municipal wastewater from the city and several communes located in

Table 1 Operational data of the Zgierz WWTP (June 2009)

\begin{tabular}{|c|c|c|c|c|}
\hline & $\begin{array}{l}\text { Mean } \\
\text { value }\end{array}$ & SD & Min & Max \\
\hline Influent flow rate $\left(\mathrm{m}^{3}\right.$ day $\left.^{-1}\right)$ & 11,770 & 3,167 & 7,550 & 20,041 \\
\hline $\begin{array}{l}\text { Recirculated activated sludge } \\
\left(\mathrm{m}^{3} \text { day }^{-1}\right)\end{array}$ & 12,208 & 1,750 & 10,380 & 17,106 \\
\hline Excess sludge $\left(\mathrm{m}^{3}\right.$ day $\left.^{-1}\right)$ & 542 & 61.3 & 407 & 645 \\
\hline Effluent flow rate $\left(\mathrm{m}^{3}\right.$ day $\left.^{-1}\right)$ & 10,822 & 3,193 & 6,710 & 19,700 \\
\hline $\begin{array}{l}\text { Internal recirculation } \\
\text { split factor }\end{array}$ & $1.5 Q_{\text {in }}$ & $0.1 Q_{\text {in }}$ & - & - \\
\hline SRT (days) & 22 & 0.7 & 20.6 & 23 \\
\hline $\mathrm{pH}$ & 7.5 & 0.13 & 7.3 & 7.8 \\
\hline Temperature $\left({ }^{\circ} \mathrm{C}\right)$ & 17 & 2.04 & 14 & 19.2 \\
\hline
\end{tabular}

the neighborhood and industrial wastewater originating mainly from small and medium enterprises. The average pollutant load to the plant corresponds to approximately 94,000 PE. The contribution of industrial wastewater is usually in the range from 10 to $15 \%$. The average inflow of wastewater is equal to $11,500 \mathrm{~m}^{3} \mathrm{day}^{-1}$, whereas the maximal inflow achieves $20,000 \mathrm{~m}^{3}$ day $^{-1}$. The treated wastewater is directly discharged to Bzura river. The Zgierz WWTP went into operation in 1995 and since then it has performed mechanical and biological treatment of wastewater. The biological step consists of one three-zone bioreactor and secondary clarifier run in the Phoredox process configuration. The volumes of anaerobic, anoxic and aerobic zone are equal to 857.5, 3,536.4 and $19,730.6 \mathrm{~m}^{3}$, respectively. The surface area of the radial secondary clarifier is $1,018 \mathrm{~m}^{2}$ (diameter equals to $36 \mathrm{~m}$ ) and its total depth is $4.5 \mathrm{~m}$. The set of measured operational data for the Zgierz WWTP in June 2009 is presented in Table 1 as an example. A schematic flow diagram of the biological step of the Zgierz WWTP is shown in Fig. 1.

\section{Data collection}

Influent, effluent, sludge excess and recirculation flow rates, $\mathrm{pH}$ and temperature were measured on-line in the Zgierz WWTP. Chemical oxygen demand (COD), biochemical oxygen demand $\left(\mathrm{BOD}_{5}\right)$, total nitrogen $\left(\mathrm{N}_{\mathrm{tot}}\right)$, total Kjeldahl nitrogen $(\mathrm{TKN})$, nitrate $\left(\mathrm{N}-\mathrm{NO}_{3}{ }^{-}\right)$, ammonium $\left(\mathrm{N}-\mathrm{NH}_{4}{ }^{+}\right)$, total phosphorus $\left(\mathrm{P}_{\text {tot }}\right)$, phosphate $\left(\mathrm{PO}_{4}{ }^{3-}\right)$, alkalinity, total suspended solids (TSS) were determined with the use of the standard methods [12]. All measurements and analyses were made within the period of data collection for the steady-state as well as dynamic calibration.

The data for the steady-state calibration were collected twice a week for a period of 1 month (June 2009) and then they were subjected to standard statistical elaboration. The confidence intervals were calculated with the help of $t$-Student test at the significance level of $95 \%$. Finally, the averaged data were introduced into BioWin. The mean flow was at the level of $11,770 \mathrm{~m}^{3} \mathrm{day}^{-1}$, the mean $\mathrm{pH}$ was equal to 7.5, the mean COD $844 \mathrm{mg} \mathrm{O}_{2} 1^{-1}$, the mean TSS
Fig. 1 Schematic flow diagram of the biological reactor at the Zgierz WWTP

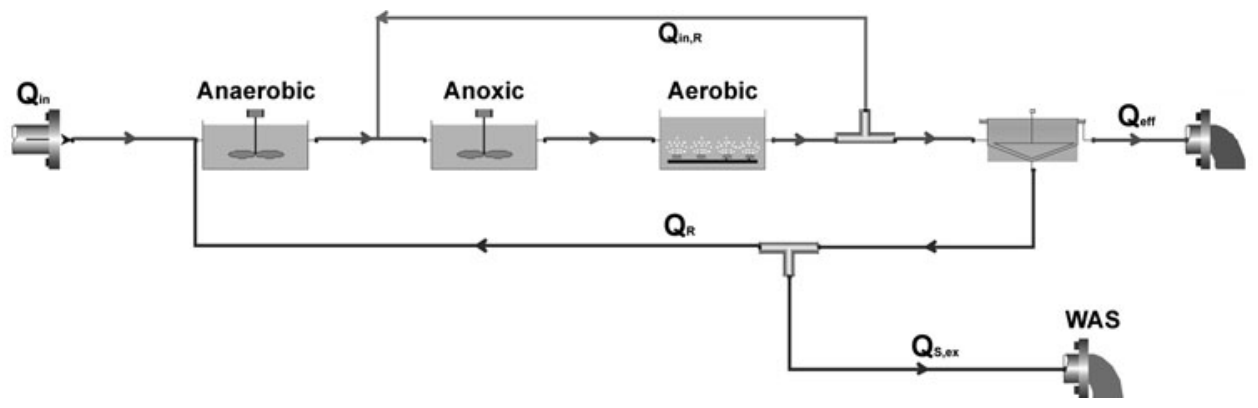




\section{BioWin Chart}

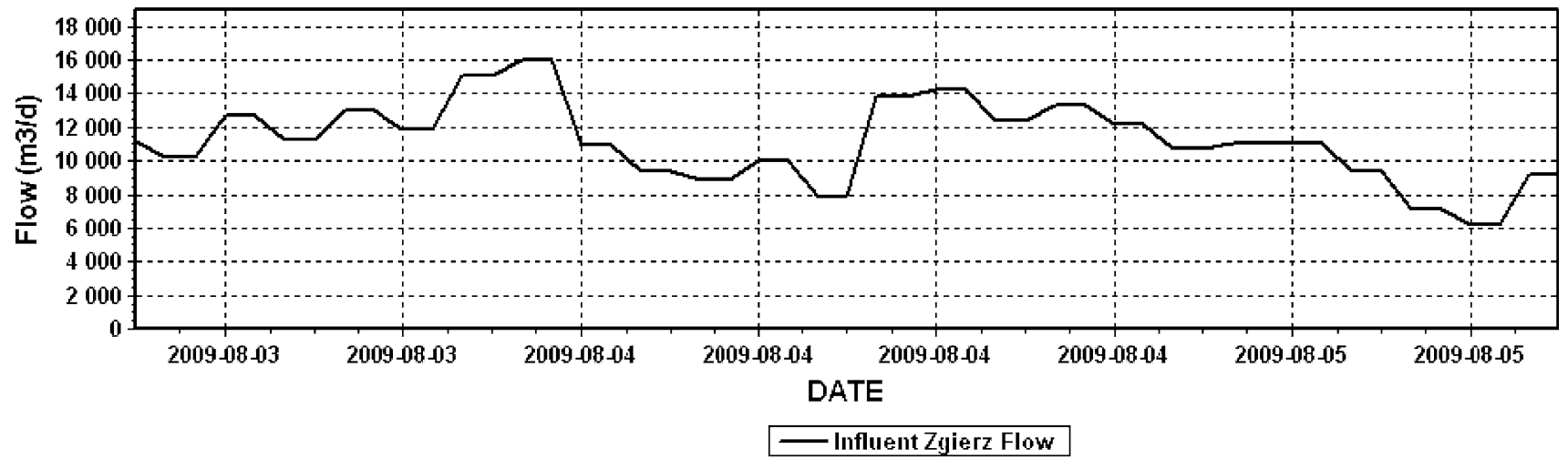

BioWin Chart

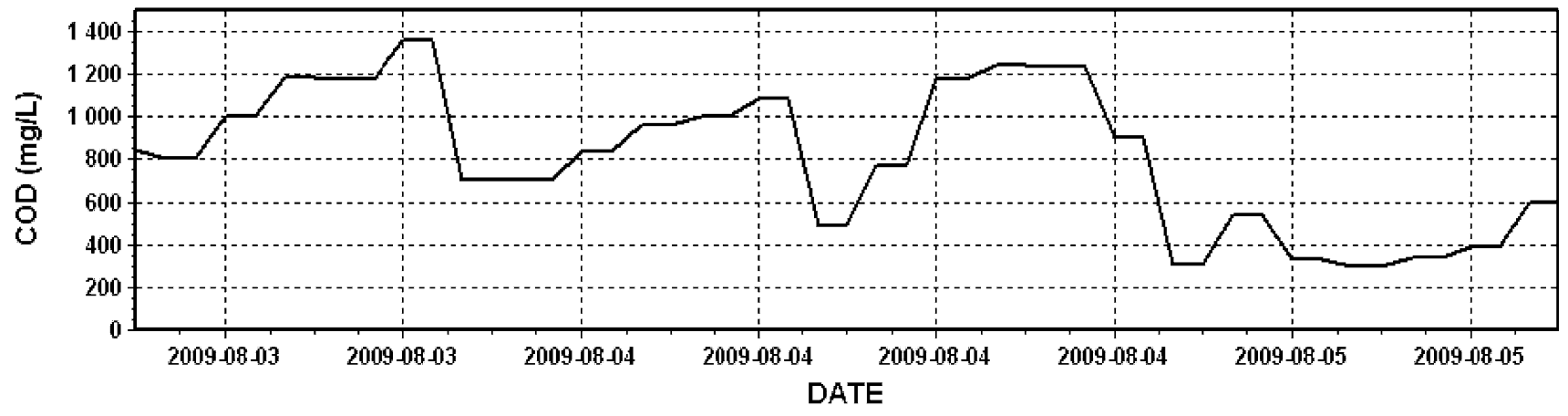

- Influent Zgierz Total COD

Fig. 2 Variations of flow rate and total COD concentration in the influent during the measurement campaign in August 2009

$365 \mathrm{mg} \mathrm{l}^{-1}$, the mean $\mathrm{N}_{\text {tot }} 48.1 \mathrm{mg} \mathrm{l}^{-1}$, the mean alkalinity $8.3 \mathrm{mmol}^{-1}$ and the mean $\mathrm{P}_{\text {tot }} 12.6 \mathrm{mg} \mathrm{l}^{-1}$.

The data for the dynamic simulations were collected for $48 \mathrm{~h}$. Wastewater samples were collected every $2 \mathrm{~h}$ from the reactor inlet and every $4 \mathrm{~h}$ from the reactor effluent. Three independent measurement campaigns were carried out in the period of June, August and September 2009. As an example, the variations in the total influent flow rate and concentration of total COD during the measurement campaign in August 2009 are presented in Fig. 2.

Model and simulation environment

The simulations of biological wastewater treatment processes were carried out with the help of BioWin v. 3.0 (EnviroSim Associates Ltd., Canada). BioWin 3.0 uses the integrated activated sludge/anaerobic digestion (AS/AD) model, which is referred to as the BioWin General Model. This model is based upon the general model for biological nutrient removal activated sludge systems, which was elaborated by Barker and Dold [13]. The model of Barker and Dold [13] can be divided into two parts: a part for the non-poly-phosphate heterotrophic organisms and autotrophic organisms, and a part for the poly-phosphate heterotrophic organisms. The first part is based on ASM1, whereas the second part describing phosphorus removal kinetics is different than it was proposed in ASMs. The BioWin AS/AD model implemented in BioWin v.3.0 is an extended version of the model described by Barker and Dold [13] with respect to activated sludge (AS) as well as anaerobic digestion (AD) model. In this work, the part of the BioWin integrated AS/AD model concerning activated sludge (AS) model was studied, thus the model was called here the BioWin AS model.

In the BioWin General Model, material balances are written for each species assuming that in the bioreactors the liquid phase is completely mixed, the gas phase is completely mixed and the gas hold-up is constant [14]. At the same time with regard to settling and separation processes, three models are included in the BioWin General Model, i.e. point separation model, ideal separation model and flux-based model [14]. In this study, the ideal separation model was used. In the BioWin General Model, 21 fractions are discriminated to specify the composition of the influent wastewater. They comprise carbonaceous substrate (five fractions), ammonium, particulate organic nitrogen, soluble non-biodegradable TKN, phosphate, nitrogen-to$\mathrm{COD}$ ratio, phosphorus-to-COD ratio and ten fractions 
representing different kinds of autochthonous biomass [14].

The BioWin AS model includes the following functional categories: (1) growth and decay of ordinary heterotrophic organisms (OHOs), (2) growth and decay of methylotrophs, (3) hydrolysis, adsorption, ammonification and assimilative denitrification, (4) growth and decay of ammonia oxidising biomass (AOB), (5) growth and decay of nitrite oxidizing biomass (NOB), (6) growth and decay of ANaerobic AMMonia OXidizers (ANAMMOX) and (7) growth and decay of phosphorus accumulating organisms (PAOs). Kinetic and stoichiometric parameters of the BioWin AS model are divided into the categories related to the groups of microorganisms taking part in biological wastewater treatment processes, i.e. AOB, NOB, OHO, ANAMMOX and PAO. In case of kinetic parameters, two additional categories are distinguished, i.e. $\mathrm{pH}$ parameters and switching functions. Due to the fact that the investigated WWTP system was operated according to the Phoredox scheme, the parameters related to ANAMMOX process had not to be subjected to sensitivity analysis. It was confirmed by the calculations of the normalized sensitivity coefficient $S_{i, j}$. For all ANAMMOX parameters, $S_{i, j}$ was equal to zero. All in all, 71 kinetic and 46 stoichiometric parameters of the BioWin AS model were analyzed. Additionally, the fractions of carbonaceous substrate expressed as COD were subjected to the sensitivity analysis. In the BioWin AS model, the following fractions of carbonaceous substrate are distinguished: readily biodegradable including acetate, acetate, non-colloidal slowly degradable, non-biodegradable soluble and non-biodegradable particulate.

The simulations were performed with the assumption of constant process temperature $17{ }^{\circ} \mathrm{C}$ and controlled Sludge retention time (SRT) (22 days) for the steady-state model calibration, and $17{ }^{\circ} \mathrm{C}$ (June 2009) or $18{ }^{\circ} \mathrm{C}$ (August and September 2009) and SRT equal to 21 days for the dynamic model calibration. The value of internal recirculation was set to the constant level of $150 \%$ of the influent flow rate. The assumed values of operating parameters reflect the conditions of the Zgierz WWTP at the period, when the data for the steady-state or dynamic calibration were collected. Before each steady-state or dynamic simulation, the correctness of input data was tested with regard to the configuration of the activated sludge system and mass balances using the tools implemented in BioWin v. 3.0.

The BioWin AS model prediction accuracy was checked by the calculation of the average relative deviation (ARD) according to the following equation [15]:

$\mathrm{ARD}=\frac{1}{N} \times \sum_{i=1}^{N} \frac{\left|\left(m_{i}-p_{i}\right)\right|}{m_{i}} \times 100 \%$ where $m_{i}$ is the measured value of the output variable, $p_{i}$ predicted value of the output variable and $N$ number of the observations. The ARD values were calculated for the results obtained in the dynamic simulations with respect to four main output variables: $\mathrm{COD}, \mathrm{BOD}_{5}, \mathrm{~N}_{\text {tot }}, \mathrm{P}_{\text {tot }}$.

Sensitivity analysis

Sensitivity analysis enables the evaluation of the extent to which the parameters used in the model calibration can influence the model outputs. Two different measures of sensitivity are calculated: the normalized sensitivity coefficient $\left(S_{i, j}\right)$ and the mean square sensitivity measure $\left(\delta_{j}^{\mathrm{msqr}}\right)$.

The normalized sensitivity coefficient $\left(S_{i, j}\right)$ is defined as a ratio of the percentage change in the output variable $\left(y_{i}\right)$ to a $10 \%$ change in the input variable $\left(x_{i}\right)$ [16]:

$S_{i, j}=\left|\frac{\Delta y_{i} / y_{i}}{\Delta x_{i} / x_{i}}\right|$

In this work, a $10 \%$ increase of the input variable was applied for the purpose of $S_{i, j}$ calculations. For each input variable, i.e. each model parameter calculations were made separately. A parameter is believed to be influential, if the value of $S_{i j}$ is equal or higher than 0.25 [17].

The second sensitivity analysis measure is the mean square sensitivity measure $\left(\delta_{j}^{\mathrm{msqr}}\right)$ introduced by Brun et al. [18]. This sensitivity measure assesses the individual parameter importance in a least squares parameter estimation context and is defined as:

$\delta_{j}^{m s q r}=\sqrt{\frac{1}{n} \sum_{i=1}^{n} S_{i, j}^{2}}$

A high value of $\delta_{j}^{\mathrm{msqr}}$ indicates that a parameter has an important influence on the simulation results, whereas the value of zero means that the simulation results do not depend on a parameter.

Seven output variables $\left(y_{i}\right)$ characterizing the quality of the effluent were taken into account in the calculations of the sensitivity analysis measures $S_{i, j}$ and $\delta_{j}^{\mathrm{msqr}}$. These were the following variables: $\mathrm{COD}, \mathrm{BOD}_{5}, \mathrm{~N}_{\text {tot }}, \mathrm{P}_{\text {tot }}, \mathrm{N}-\mathrm{NH}_{4}{ }^{+}$, $\mathrm{N}-\mathrm{NO}_{3}{ }^{-}$and $\mathrm{TKN}$.

\section{Results and discussion}

Steady-state and dynamic calibrations of the model

The simulations performed with the default values of kinetic and stoichiometric parameters of the BioWin AS model revealed discrepancies between the measured and simulated values of the output variables. In the simple 
Table 2 Calibrated values of kinetic and stoichiometric parameters

\begin{tabular}{|c|c|c|c|c|c|}
\hline Parameter & Unit & $\begin{array}{l}\text { Default value } \\
\text { in BioWin }\end{array}$ & $\begin{array}{l}\text { Calibrated value } \\
\text { (steady-state) }\end{array}$ & $\begin{array}{l}\text { Calibrated value } \\
\text { (dynamic) }\end{array}$ & $\begin{array}{l}\text { Literature } \\
\text { values [1] }\end{array}$ \\
\hline \multicolumn{6}{|l|}{$\mathrm{AOB}$} \\
\hline$b_{\text {aerob,A }}$ & day $^{-1}$ & 0.17 & 0.23 & 0.21 & $0.05-0.15$ \\
\hline \multicolumn{6}{|l|}{$\mathrm{OHO}$} \\
\hline$K_{\mathrm{S}}$ & $\operatorname{mg~COD~} 1^{-1}$ & 5 & 15 & 15 & 4 \\
\hline$b_{\mathrm{H}}$ & day $^{-1}$ & 0.62 & 0.9 & 0.8 & $0.2-0.4$ \\
\hline$Y_{\mathrm{H}}$ & $\mathrm{mg}$ COD mg COD ${ }^{-1}$ & 0.666 & 0.74 & 0.7 & 0.625 \\
\hline$\mu_{\operatorname{maxH}}$ & day $^{-1}$ & 3.2 & - & 5.2 & $3-6$ \\
\hline \multicolumn{6}{|l|}{ PAO } \\
\hline$\mu_{\mathrm{maxPAO}}$ & day $^{-1}$ & 0.95 & - & 0.8 & $0.67-1$ \\
\hline$Y_{\mathrm{PAO}, \mathrm{aerob}}$ & mg COD mg COD ${ }^{-1}$ & 0.635 & - & 0.5 & 0.625 \\
\hline$Y_{\mathrm{PAO}, \text { anox }}$ & $\mathrm{mg}$ COD mg COD ${ }^{-1}$ & 0.52 & - & 0.5 & - \\
\hline$Y_{\mathrm{P} / \mathrm{PHA}, \mathrm{seq}}$ & $\mathrm{mg}$ COD mg COD ${ }^{-1}$ & 0.889 & - & 0.959 & - \\
\hline$Y_{\mathrm{P} / \text { acetic }}$ & $\mathrm{mg} \mathrm{P} \mathrm{mg} \mathrm{COD}{ }^{-1}$ & 0.49 & - & 0.54 & 0.4 \\
\hline
\end{tabular}

steady-state simulations, these discrepancies concerned mainly the removal of organic carbon substances (COD, $\mathrm{BOD}_{5}$ ), whereas in the dynamic simulations they also concerned nitrogen and phosphorus compounds removal $\left(\mathrm{N}_{\text {tot }}, \mathrm{P}_{\text {tot }}, \mathrm{N}-\mathrm{NH}_{4}{ }^{+}, \mathrm{N}-\mathrm{NO}_{3}{ }^{-}, \mathrm{TKN}\right)$, i.e. almost all output variables. It meant that in both cases the model calibration was necessary.

In Table 2, the values of calibrated parameters for the steady-state and dynamic calibrations are compared. Additionally, the literature values or ranges for these parameters, if available, are included in Table 2. In order to adjust the simulated values of variables characterizing the effluent to the measured ones, four parameters had to be calibrated under the steady-state conditions, while in the dynamic conditions these were ten parameters. Three $\left(K_{\mathrm{S}}\right.$, $\left.Y_{\mathrm{H}}, b_{\mathrm{H}}\right)$ out of four parameters calibrated in the steady-state simulations were associated with growth and decay of OHOs (Table 2). The discrepancies between the measured and simulated values of $\mathrm{COD}$ and $\mathrm{BOD}_{5}$ in the effluent made the adjustment of such parameters as $K_{\mathrm{S}}, Y_{\mathrm{H}}$ and $b_{\mathrm{H}}$ necessary. The influent to the Zgierz WWTP contained a significant amount of industrial wastewater (mainly from textile industry) and the affinity of this kind of substrate is lower than for typical municipal wastewater [19]. As a result, the default value of $K_{\mathrm{S}}$ had to be elevated to $15 \mathrm{mg} \mathrm{COD}^{-1}$.

A dynamic calibration is much more complicated than a steady-state calibration because it aims at the description of concentration profiles of output variables in time. In order to perform the dynamic simulations more data, including hydraulic data, need to be introduced to a model $[2,20]$. Thus, each step of the dynamic calibration, starting from data collection, is a requiring and timeconsuming task.
The calibration of the BioWin AS model was performed upon the data obtained in June 2009 campaign, and then the model was validated on the basis of two independent sets of data obtained in August and September 2009. The parameters, which were calibrated in the dynamic simulations, were associated with different groups of organisms, i.e. OHOs, AOBs and PAOs. However, half of them was associated with PAOs and these were mainly stoichiometric coefficients $\left(Y_{\mathrm{PAO}, \text { aerob }}, Y_{\mathrm{PAO}, \text { anox }}, Y_{\mathrm{P} / \mathrm{PHA} \text {,seq }}, Y_{\mathrm{P} / \text { acetic }}\right)$. In the steady-state simulations, the discrepancies between measured and simulated values of $\mathrm{P}_{\text {tot }}$ in the effluent were of little importance so there was no need to calibrate parameters related to PAOs. At the same time, in the dynamic conditions, the calibration of these parameters was required in order to reflect the changes of phosphorus concentration in the effluent properly. Four out of five other parameters calibrated under the dynamic conditions, i.e. $K_{\mathrm{S}}, Y_{\mathrm{H}}, b_{\mathrm{H}}, b_{\text {aerob,A }}$ were the same as in the steady-state calibration (Table 2). Additionally, maximum specific growth rate of OHOs under aerobic conditions $\left(\mu_{\operatorname{maxH}}\right)$ needed adjustment in the dynamic calibration. Its value was increased from 3.2 to $5.2 \mathrm{day}^{-1}$; however, it still remained in the range of $\mu_{\operatorname{maxH}}$ values used in ASMs [1]. At the same time, the calibrated value of $b_{\mathrm{H}}$ was higher than the default value (Table 2) as well as its literature value [1]. The relatively high decay coefficients $\left(b_{\mathrm{H}}\right.$ and $b_{\text {aerob,A }}$ ) were most probably caused by the long SRT (above 20 days). According to Grady et al. [21], biomass decay increases at longer SRTs. The SRT usually varies from 5 to 15 days in the conventional activated sludge systems [22]. Moreover, comparing the calibrated values of parameters with the literature ones (Table 2), it should be noticed that the latter were assumed for wastewater containing total COD of $260 \mathrm{mg} \mathrm{O}_{2} \mathrm{l}^{-1}$, total nitrogen 


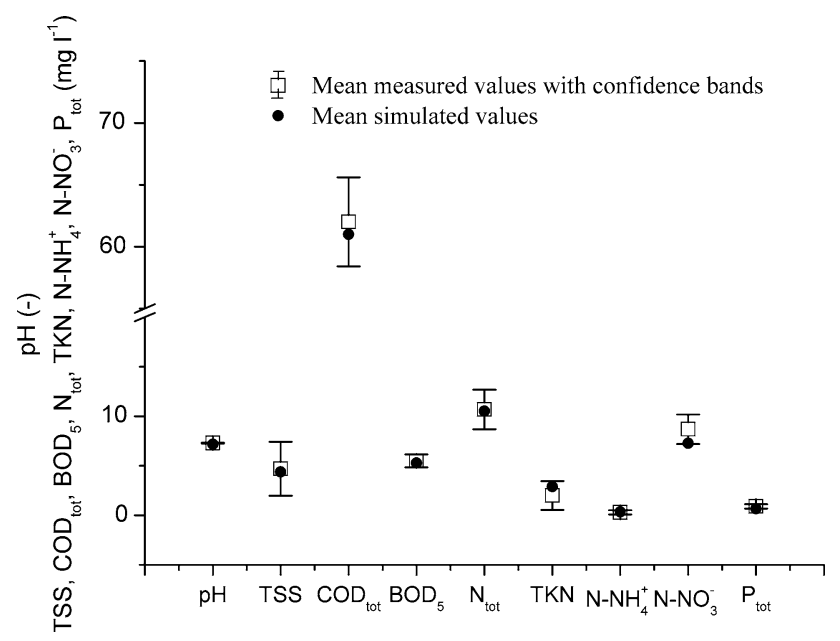

Fig. 3 Measured versus simulated values of the selected variables in the effluent under the steady-state conditions

$25 \mathrm{mg} \mathrm{N}^{-1}$ and TSS $140 \mathrm{mg} \mathrm{l}^{-1}$ [1]. Influent to the Zgierz WWTP contained the mean total COD of $844 \mathrm{mg} \mathrm{O}_{2} \mathrm{l}^{-1}$, the mean $\mathrm{N}_{\text {tot }}$ of $48.1 \mathrm{mg} \mathrm{l}^{-1}$ and the mean TSS of $365 \mathrm{mg} \mathrm{l}^{-1}$. The significant differences in the composition between the wastewater studied here and typical municipal wastewater [1] contributed to the discrepancies between the values of some calibrated and literature parameters (Table 2).

The simultaneous changes of $b_{\mathrm{H}}$ and $\mu_{\mathrm{maxH}}$ in the dynamic conditions are mainly connected with the diversity of activated sludge biomass. It was observed that certain conditions, for example, an excess of readily degradable substrate, favor the growth of fast-growing microorganisms (increase of $\mu_{\operatorname{maxH}}$ ), whereas the decay of other microorganisms can be at the same time high (increase of $b_{H}$ ) $[22,23]$.

In order to evaluate the quality of calibration of the BioWin AS model under the steady-state conditions, it was proposed to check, if the simulated value of an output variable was included in the confidence interval estimated for its measured value of the effluent. If it was a case, the simulation was successful because there was no significant statistical difference between the simulated and measured values of the investigated variable [20]. It occurred that each of the simulated output variables was included in the confidence interval estimated for the respective measured variable under the steady-state conditions (Fig. 3).

In the dynamic conditions, the quality of the calibration of the BioWin AS model was differently evaluated. The values of confidence intervals for the output variables in the steady-state calibration illustrated the variation of these variables around the mean, whereas in the dynamic calibration, the confidence intervals of the output variables can express only the accuracy of the analytical methods. It is due to the fact that a dynamic simulation aimed at showing the changes of the actual value of output variables in time. In Figs. 4, 5 and 6, the changes of simulated and measured output variables representing carbon $\left(\mathrm{BOD}_{5}\right)$, nitrogen $\left(\mathrm{N}_{\mathrm{tot}}\right)$ and phosphorus substances $\left(\mathrm{PO}_{4}{ }^{3-}\right)$ in the dynamic simulations after calibration are presented. In general, the agreement between the measured and simulated values of the output variables in each of three series was achieved (Figs. 4, 5, 6). The discrepancies between the measured and simulated values of the output variables did not exceed $20 \%$. Additionally, the goodness-of-fit for the dynamic simulations was quantified by the ARDs. Their values for COD, $\mathrm{BOD}_{5}, \mathrm{~N}_{\text {tot }}$ and $\mathrm{P}_{\text {tot }}$ were, respectively, in the ranges from 7.14 to $14.74,10.2$ to $14.89,8.9$ to 14.87 and 15.12 to $19.18 \%$. These results confirmed that the dynamic calibration was performed correctly.

It should be emphasized that the aim of a dynamic calibration is not to predict each value of an individual output variable, but to predict a trend of its changes. In this context, the performed dynamic calibration was fully successful. Moreover, the experts claim that it is more important to predict the changes of all key-output variables at the acceptable level of tolerance than to predict the changes of only one or two output variables ideally [5].

\section{Sensitivity analysis}

In this study, 71 kinetic and 46 stoichiometric parameters of the Biowin AS model were subjected to sensitivity analysis. So were five fractions of carbonaceous substrate. To the model parameters belonged the ones associated with growth and decay of AOB, NOB, OHOs and PAOs as well as the kinetic parameters responsible for $\mathrm{pH}$ inhibition and switching functions. Sensitivity analysis revealed that among 117 kinetic and stoichiometric parameters, which were studied, 20 can be regarded as sensitive. With regard to the fractions of carbonaceous substrate, it occurred that two of them were sensitive. In Table 3, the most sensitive parameters and fractions in the steady-state and dynamic calibrations are presented. Comparing these results, it can be noticed that in both calibrations, the same parameters occurred to be sensitive. The differences concerned only four parameters (Table 3). All parameters, excluding $k_{\mathrm{a}}$, sensitive in the steady-state calibration occurred to be sensitive in the dynamic calibration, too. Additionally, there were three parameters, i.e. $K_{\mathrm{S} \text {,hydrolysis }}, Y_{\mathrm{H} \text {,anoxic }}$, $b_{\mathrm{PAO}}$, which proved to be sensitive under the dynamic conditions (Table 3).

The sensitive model parameters represented kinetic and stoichiometric parameters associated with growth and decay of AOB, OHOs, PAOs and one of these parameters belonged to switching functions $\left(K_{\mathrm{PP}}\right)$ (Table 3). Parameters expressing growth and decay of NOB were sensitive neither in the steady-state nor in the dynamic calibration. 


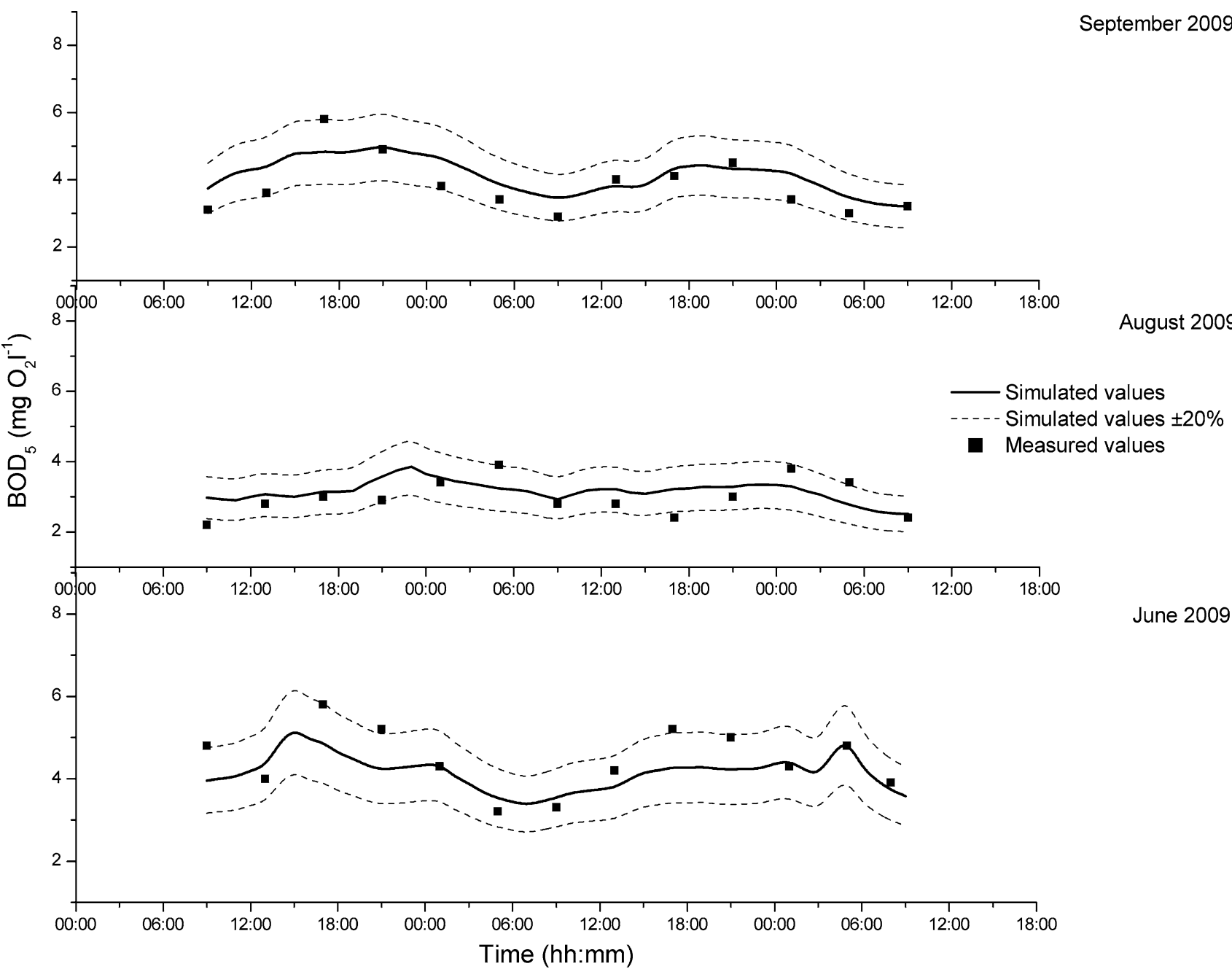

Fig. 4 Measured versus simulated values of $\mathrm{BOD}_{5}$ in the effluent under the dynamic conditions

Nevertheless, when nitrite is incorporated into ASMs as an intermediate product of biological processes, better description of nitrogen compounds removal from wastewater can be obtained [24].

Two fractions of carbonaceous substrate, i.e. readily biodegradable COD and non-biodegradable soluble COD, were sensitive in the steady-state and dynamic calibrations (Table 3 ). The change of readily biodegradable fraction influenced phosphorus concentration in the effluent. It is connected with the mechanism of biological phosphorus removal from wastewater. Readily degradable compounds are necessary to form poly-hydroxy-alkanoates (PHA). At the same time, the value of COD in the effluent depended on the fraction of non-biodegradable soluble COD. The higher the fraction of $F_{\text {us }}$ was, the higher COD of the effluent was.

Most of the parameters indicated as sensitive in this study were associated with growth and decay of PAOs (Table 3). These were kinetic as well as stoichiometric parameters. Several other studies emphasized the influential role of the model parameters related to PAOs in ASMs $[15,18,25]$. In the BioWin AS model, the role of parameters connected with PAOs is even greater than in wellknown ASM models. Four of parameters associated with PAOs found in this work as sensitive, i.e. $\mu_{\operatorname{maxPAO}}, K_{\mathrm{S} \text {,PAO }}$, $b_{\mathrm{PAO}}, Y_{\mathrm{P} / \text { acetic }}$ were used in ASM2d and ASM3P models. Some of them, as for example $b_{\mathrm{PAO}}$, were already believed to be very influential parameters [18]. At the same time, other five parameters related to PAOs (Table 3) are characteristic for the BioWin AS model and the knowledge about their interpretation and determination is in shortage.

Parameters associated with PAOs found themselves on the top of the lists of ten most sensitive parameters. Two lists based upon the mean square sensitivity measure $\delta_{j}^{\mathrm{msqr}}$ calculations were prepared. One of them referred to the steady-state calibration, while the second to the dynamic calibration (Table 4). In both rankings, the stoichiometric coefficients related to PAOs were on the first places. These 


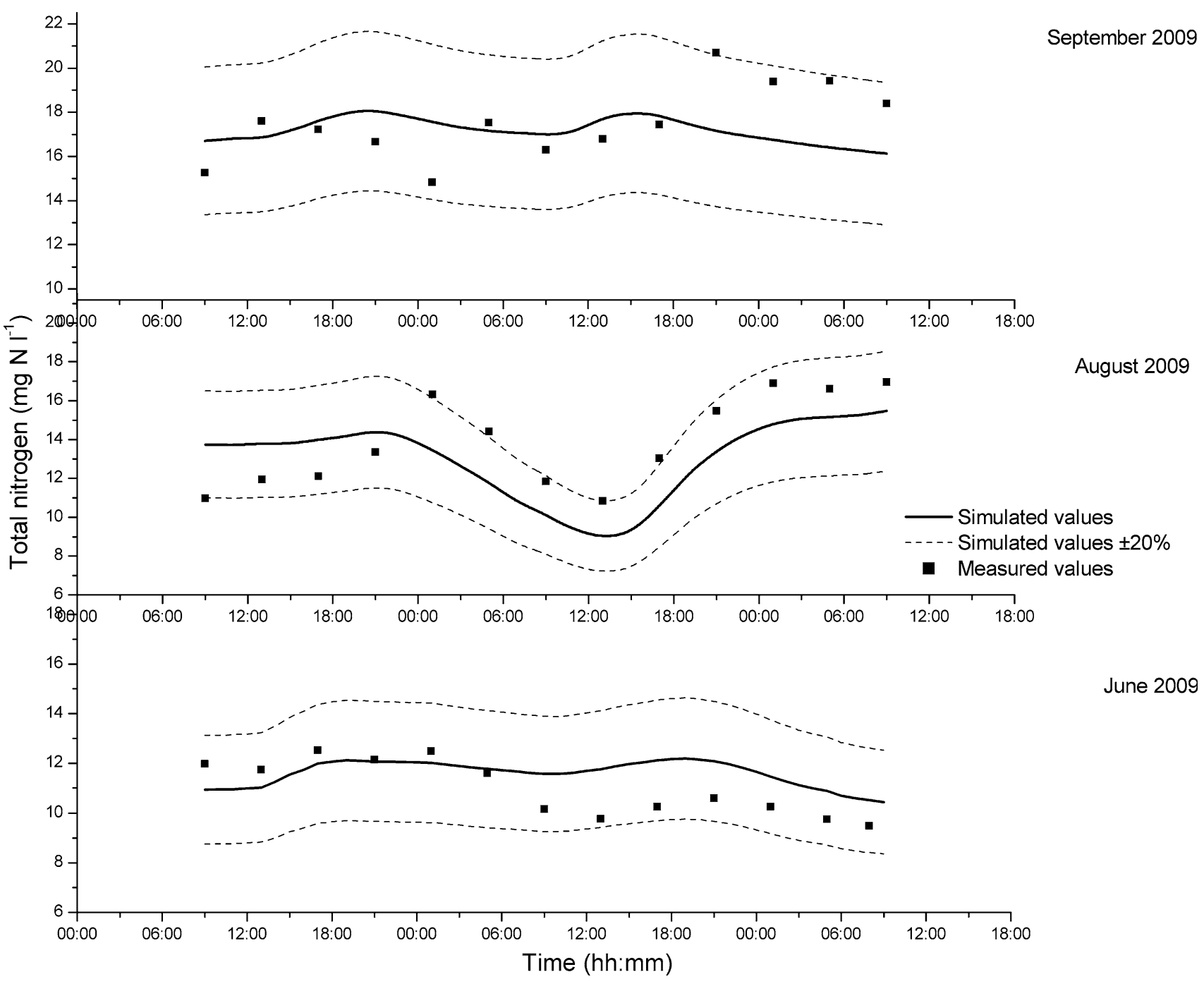

Fig. 5 Measured versus simulated values of $\mathrm{N}_{\text {tot }}$ in the effluent under the dynamic conditions

were $Y_{\mathrm{P} / \mathrm{PHA}}$,seq, $Y_{\mathrm{P} / \text { acetic }}$ and $Y_{\text {lowPP }}$ (Table 4). The stoichiometric coefficient $Y_{\mathrm{P} / \text { acetic }}$ is defined as the amount of phosphorus released for $1 \mathrm{mg}$ of acetate sequestrated in the form of PHA. Its default value is equal to $0.49 \mathrm{mg} \mathrm{P} \mathrm{mg} \mathrm{COD}{ }^{-1}$. $Y_{\mathrm{P} / \text { acetic }}$ corresponds with the yield of phosphorus release to substrate uptake $Y_{\mathrm{PO}_{4}}$, which was used in ASM2, ASM2d and ASM3P models [1, 26]. $Y_{\text {lowPP }}$ expresses the fraction of phosphorus stored in the releasable poly-phosphate-P and its default value is equal to $0.94 \mathrm{mg} \mathrm{P} \mathrm{mg} \mathrm{P}^{-1}$. The rest of phosphorus is stored as the high molecular weight non-releasable poly-phosphate-P. This stoichiometric coefficient is characteristic for the BioWin AS model. Its value cannot exceed 1 and seems to be relatively stable for PAOs. The last of three most influential parameters $Y_{\mathrm{P} / \mathrm{PHA} \text {,seq }}$ expresses the amount of PHA stored when $1 \mathrm{mg}$ of acetate or propionate is sequestrated and, similarly to $Y_{\text {lowPP }}$ is characteristic only for the BioWin AS model.
Out of kinetic and stoichiometric parameters of ASMs and ASM-based models, the parameters related to PAOs are less recognized than these related to OHOs or AOBs [27-29]. It is the most probably due to the fact that biological phosphorus removal was later incorporated in wastewater treatment technology and modeling. Although several attempts have been made in order to elaborate the procedures to determine the parameters for PAOs, these procedures still need significant corrections and complementation [30, 31].

Comparing the two rankings of the most sensitive parameters, it must be stated that half of the top ten parameters represented kinetic parameters and the other half stoichiometric parameters (Table 4). What is also important, the stoichiometric coefficients were exactly the same in both lists of the top ten most sensitive parameters and they outclassed kinetic parameters. The fractions of carbonaceous substrate occurred not to belong to the top 


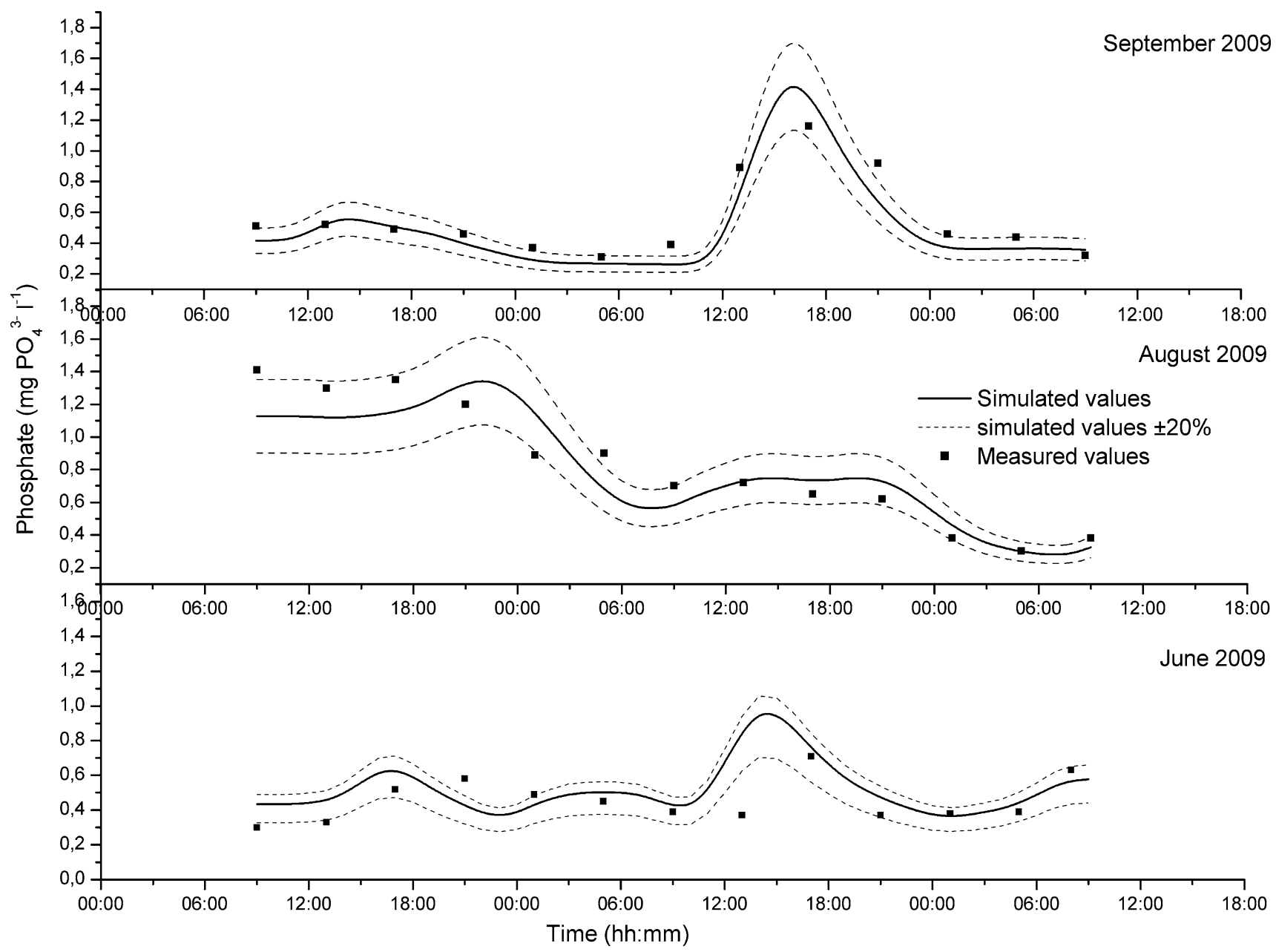

Fig. 6 Measured versus simulated values of phosphate $\left(\mathrm{PO}_{4}{ }^{3-}\right)$ in the effluent under the dynamic conditions

ten sensitive parameters either in the steady-state or the dynamic calibration. The small discrepancies between the rankings just concerned the kinetic parameters (Table 4). In the steady-state calibration, kinetic parameters associated with AOBs $\left(b_{\text {aerob,A }}, K_{\mathrm{NH}_{4}}\right)$ occurred to be more sensitive, while in the dynamic calibration these were the parameters related to PAOs $\left(\mu_{\text {maxP-limited }}, K_{\mathrm{PP}}\right)$. However, three kinetic parameters $\mu_{\operatorname{maxA}}, \mu_{\operatorname{maxH}}$ and $b_{\mathrm{H}}$ were present in both rankings (Table 4 ). Similar results of the rankings indicate that the identification of the most sensitive parameters in the simpler steady-state calibration would be very helpful in the calibration of the BioWin AS model under the dynamic conditions.

\section{Conclusions}

The calibration of the BioWin AS model performed in this study occurred to be successful. The steady-state calibration required the adjustment of only four parameters, whereas the dynamic calibration ten parameters. In both
Table 3 List of sensitive parameters and fractions in the steady-state and dynamic calibrations

\begin{tabular}{lll}
\hline Parameter & Steady-state calibration & Dynamic calibration \\
\hline AOB & & \\
Kinetic & & + \\
$\mu_{\operatorname{maxA}}$ & + & + \\
$K_{\mathrm{NH}}$ & + & + \\
$b_{\text {aerob,A }}$ & + & \\
OHO & & \\
Kinetic & & + \\
$\mu_{\text {maxH }}$ & + & + \\
$K_{\mathrm{S}}$ & + & + \\
$b_{\mathrm{H}}$ & + & - \\
$k_{\mathrm{a}}$ & + & + \\
$K_{\mathrm{S}, \text { hydrolysis }}$ & - & \\
Stoichiometric & & + \\
$Y_{\mathrm{H}}$ & + & \\
$Y_{\mathrm{H}, \text { anoxic }}$ & - & \\
PAO & & \\
\hline
\end{tabular}


Table 3 continued

\begin{tabular}{lll}
\hline Parameter & Steady-state calibration & Dynamic calibration \\
\hline Kinetic & & \\
$\mu_{\text {maxPAO }}$ & + & + \\
$\mu_{\text {maxPlimited }}$ & + & + \\
$K_{\mathrm{S}, \text { PAO }}$ & + & + \\
$K_{\mathrm{S} \text { Plimited }}$ & + & + \\
$b_{\text {PAO }}$ & - & + \\
Stoichiometric & & \\
$Y_{\mathrm{P} / \text { PHA,aerobic }}$ & + & + \\
$Y_{\text {PHA,seq }}$ & + & + \\
$Y_{\mathrm{P} / \text { acetic }}$ & + & + \\
$Y_{\text {lowPP }}$ & + & + \\
Switches & & \\
$K_{\mathrm{PP}}$ & + & + \\
Fractions of carbonaceous substrate & \\
$F_{\text {bs }}$ & + & + \\
$F_{\text {us }}$ & + & + \\
\hline
\end{tabular}

Table 4 Top ten kinetic and stoichiometric parameters importance rankings: (1) for the calibrated model under the dynamic conditions, (2) for the calibrated model under the steady-state conditions

\begin{tabular}{|c|c|c|c|}
\hline \multicolumn{2}{|l|}{ (1) } & \multicolumn{2}{|l|}{ (2) } \\
\hline Parameter & $\delta^{\mathrm{msqr}}$ & Parameter & $\delta^{\mathrm{msqr}}$ \\
\hline$Y_{\mathrm{P} / \mathrm{PHA} \text {,seq }}$ & 2.184 & $Y_{\mathrm{P} / \text { acetic }}$ & 1.022 \\
\hline$Y_{\mathrm{P} / \text { acetic }}$ & 1.259 & $Y_{\text {lowPP }}$ & 0.833 \\
\hline$Y_{\text {lowPP }}$ & 1.036 & $Y_{\mathrm{P} / \mathrm{PHA} \text {,seq }}$ & 0.717 \\
\hline$Y_{\mathrm{P} / \mathrm{PHA}, \text { aerobic }}$ & 0.839 & $Y_{\mathrm{H}}$ & 0.663 \\
\hline$Y_{\mathrm{H}}$ & 0.724 & $Y_{\mathrm{P} / \mathrm{PHA}, \text { aerobic }}$ & 0.613 \\
\hline$\mu_{\operatorname{maxA}}$ & 0.561 & $\mu_{\operatorname{maxA}}$ & 0.572 \\
\hline$b_{\mathrm{H}}$ & 0.384 & $b_{\text {aerob, } \mathrm{A}}$ & 0.426 \\
\hline$\mu_{\text {maxP-limited }}$ & 0.336 & $K_{\mathrm{NH}_{4}}$ & 0.425 \\
\hline$K_{\mathrm{PP}}$ & 0.336 & $b_{\mathrm{H}}$ & 0.420 \\
\hline$\mu_{\operatorname{maxH}}$ & 0.319 & $\mu_{\operatorname{maxH}}$ & 0.397 \\
\hline
\end{tabular}

calibrations a successful agreement between the measured and simulated values of the output variables expressing the concentrations of carbon, nitrogen and phosphorous compounds in the effluent was achieved. Sensitivity analysis of the BioWin AS model parameters revealed that upon the calculations of normalized sensitivity coefficient $\left(S_{i, j}\right) 17$ (steady-state) or 19 (dynamic conditions) kinetic and stoichiometric parameters, and 2 fractions of carbonaceous substrate are sensitive. What is more important, the parameters sensitive in the steady-state calibration also occurred to be sensitive in the dynamic calibration. Most of them are associated with growth and decay of heterotrophs (OHOs and PAOs).

The rankings of ten most sensitive parameters established on the basis of calculations of the mean square sensitivity measure $\left(\delta_{j}^{\mathrm{msqr}}\right)$ show the agreement in the sensitivity of parameters in the steady-state and dynamic conditions. It means that sensitivity analysis for the steadystate conditions can significantly support the dynamic calibration. This work proves that stoichiometric coefficients stronger influence the results of modeling than kinetic parameters. Apart from the yield coefficient of OHOs under aerobic conditions $\left(Y_{\mathrm{H}}\right)$, these are mainly yield coefficients related to PAOs. For some of them, the methods of their evaluation should be elaborated.

Acknowledgments This work was financed by Ministry of Science and Higher Education (Republic of Poland), project no. N N209 102637.

Open Access This article is distributed under the terms of the Creative Commons Attribution Noncommercial License which permits any noncommercial use, distribution, and reproduction in any medium, provided the original author(s) and source are credited.

\section{References}

1. Henze M, Gujer W, Mino T, van Loosdrecht MCM (2000) Activated sludge models ASM1, ASM2, ASM2d and ASM3. IWA Science and Technical Report No. 9. IWA Publishing, London

2. Gernaey KV, van Loosdrecht MCM, Henze M, Lind M, Jorgensen SB (2004) Activated sludge wastewater treatment plant modelling and simulation: state of the art. Environ Modell Softw 19(9):763-783

3. Meijer SCP, van der Spoel H, Susanti S, Heijnen JJ, van Loosdrecht MCM (2002) Error diagnostics and data reconciliation for activated sludge modelling using mass balances. Wat Sci Technol 45(6): 145-156

4. Hulsbeek JJW, Kruit J, Roeleveld PJ, van Loosdrecht MCM (2002) A practical protocol for dynamic modeling of activated sludge systems. Water Sci Technol 45(6):127-136

5. Melcer H, Dold PL, Jones RM, Bye CM, Takacs I, Stensel HD, Wilson AW, Sun P, Bury S (2003) Methods for wastewater characterization in activated sludge modelling. Water Environment Research Foundation (WERF), Alexandria

6. Vanrolleghem PA, Insel G, Petersen B, Sin G, De Pauw D, Nopens I, Weijres S, Gernaey K (2003) A comprehensive model calibration procedure for activated sludge models. In: Proceedings of WEFTEC 2003, 76th annual technical exhibition and conference, 11-15 October 2003, Los Angeles, CA, USA

7. Langergraber G, Rieger L, Winkler S, Alex J, Wiese J, Owerdieck C, Ahnert M, Simon J, Maurer M (2004) A guideline for simulation studies of wastewater treatment plants. Water Sci Technol 50(7):131-138

8. Sin G, van Hulle SWH, De Pauw DJW, van Griensven A, Vanrolleghem PA (2005) A critical comparison of systematic calibration protocols for activated sludge models: a SWOT analysis. Water Res 39(12):2459-2474 
9. Sin G, Gernaey KV, Neumann MB, van Loosdrecht MCM, Gujer W (2009) Uncertainty analysis in WWTP model applications: a critical discussion using an example from design. Water Res 43(11):2894-2906

10. Nuhoglu A, Keskinler B, Yildiz E (2005) Mathematical modelling of the activated sludge process-the Erzincan case. Process Biochem 40:2467-2473

11. Béline F, Boursier H, Daumer ML, Guiziou F, Paul E (2007) Modelling of biological processes during aerobic treatment of piggery wastewater aiming at process optimisation. Biores Technol 98:3298-3308

12. APHA-AWWA-WPCF (1995) Standard methods for the examination of water and wastewater, 19th edn. APHA-AWWAWPCF, Washington DC

13. Barker PS, Dold PL (1997) General model for biological nutrients removal activated-sludge systems: model presentation. Water Environ Res 69(5):969-984

14. EnviroSim Associates Ltd (2008) User manual for BioWin 3.0. EnviroSim Associates Ltd

15. Makinia J, Rosenwinkel KH, Spering V (2006) Comparison of two model concepts for simulation of nitrogen removal at a full scale biological nutrient removal pilot plant. J Environ Eng ASCE 132(4):476-487

16. U.S. EPA (1987) QUAL2E-the enhanced stream water quality model EPA/823/B-95/003. Environmental Research Laboratory, Athens

17. Petersen B, Gernaey K, Henze M, Vanrolleghem PA (2002) Evaluation of an ASM1 model calibration procedure on a municipal-industrial wastewater treatment plant. J Hydroinform 4:15-38

18. Brun R, Kuhni M, Siegrist H, Gujer W, Reichert P (2002) Practical identifiability of ASM2d parameters-systematic selection and tuning of parameters subsets. Water Res 36(16): 4113-4127

19. Liwarska-Bizukojc E, Scheumann R, Drews A, Bracklow U, Kraume M (2008) Effect of anionic and nonionic surfactants on the kinetics of the aerobic heterotrophic biodegradation of organic matter in industrial wastewater. Water Res 42(4-5): 923-930

20. Petersen B, Gernaey K, Henze M, Vanrolleghem PA (2003) Calibration of activated sludge models: a critical review of experimental designs. In: Agathos SN, Reineke W (eds) Biotechnology for the environment: wastewater treatment and modelling: waste gas handling. Kluwer, Dordrecht

21. Grady CPL Jr, Daigger GT, Lim HC (1999) Biological wastewater treatment. Marcel Dekker, New York

22. Bitton G (2005) Wastewater microbiology, 3rd edn. John Wiley \&Sons Inc., Hoboken

23. Novák L, Larrea L, Wanner J (1994) Estimation of maximum specific growth rate of heterotrophic and autotrophic biomass: a combined technique of mathematical modelling and batch cultivations. Water Sci Technol 30(11):171-180

24. Kaelin D, Manser R, Rieger L, Eugster J, Rottermann K (2009) Extension of ASM3 for two-step nitrification and denitrification and its calibration and validation with batch tests and pilot scale plant. Water Res 43:1680-1692

25. Sun P, Wang R, Fang Z (2009) Fully coupled activated (FCASM): model development. Biores Technol 100:4632-4641

26. Rieger L, Koch G, Kühni M, Gujer W, Siegrist H (2001) The EAWAG BIO-P module for activated sludge model no. 3. Water Res 35(16):3887-3903

27. Kappeler J, Gujer W (1992) Estimation of kinetic parameters of heterotrophic biomass under aerobic conditions and characterization of wastewater for activated sludge modelling. Water Sci Technol 25(6):125-139

28. Vaiopoulou AE, Aivasidis BA (2007) A semi-batch on-line method for biokinetics determination in an enhanced biological phosphorus removal system. In: Proceedings of European congress of chemical engineering (ECCE-6), 16-20 September 2007, Copenhagen, Denmark

29. Damayanti A, Ujang Z, Salim MR, Olsson G, Sulaiman AZ (2010) Respirometric analysis of activated sludge models from palm and oil effluent. Biores Technol 101:144-149

30. Pala A, Bölükbas Ö (2005) Evaluation of kinetic parameters for biological CNP removal from a municipal wastewater through batch tests. Process Biochem 40(2):629-635

31. Ferrai M, Guglielmi G, Andreotolla G (2010) Modelling respirometric tests for the assessment of kinetic and stoichiometric parameters on MBBR biofilm for municipal wastewater treatment. Environ Modell Softw 25(5):626-632 